\title{
The Development of Inquiry Learning on Analytical Chemistry Lab II at Diploma of Analytical Chemistry
}

\author{
Thorikul Huda ${ }^{a, *}$, Yuli Rohyami ${ }^{a}$ \\ ${ }^{a}$ Diploma of Analytical Chemistry, Islamic University of Indonesia \\ ${ }^{*}$ Corresponding author: thorikul.huda@uii.ac.id
}

\begin{abstract}
The development of inquiry learning has been performed on Analytical Chemistry Lab II at Diploma of Analytical Chemistry. This study is a classroom action research using 68 students of semester $2^{\text {nd }}$. Inquiry learning development that has been implemented in general has given the results of innovation learning in vocational education programs. Development of learning innovation is particularly relevant to the competency certification systems that have been developed in Professional Certification Agency (LSP UII). The lesson plan has been done contributed to improvements in the design of learning that refers to the Indonesian National Competency Standards in 2015.

The development of inquiry learning can help the achievement of student competence. Achievement of competence from the knowledge aspect is done by using written test response test data, while from the attitude and skill aspect is measured by test practice test value. Mean of achievement of knowledge competence is 57.34 and mean of attainment of competency from attitude and skill aspect is 72.06 . Competence is an assessment of knowledge, attitudes, and skills that can be measured. Chemical Lab Learning Analysis II is a process of inquiry learning conducted through a series of experiments so that the learning process should be supported by the understanding of the theory concepts that get in the classroom. Lab learning is focused on achieving the competence of work attitude which gives birth to a standardized work culture and skills must be supported with sufficient knowledge.

Data supporting the achievement of student competence can be measured through self-assessment in three competency units, that is MSL973002A prepare work solution, MSL974001A prepare, standardize, and use solution and MSL974003A perform testing and chemical procedure that is in accordance with this course with SKKNI Field Laboratory Testing Services from Australian Laboratory Operations Training Package (MSL09). Assessment is done after the students follow the learning process inquiry with the development of learning video. Achievement of students' average student competency Semester 2nd of Chemical Analyst Department at three units of competence is $78.52 \%$. During the learning process lab, students are given learning tasks in preparing work solutions including preparing, standardizing and using the solution. Achievement rates on these units were $77.30 \%$ and $79.51 \%$.

The result of the learning development that has been done can give the improvement of the learning result according to the expected target. Learning outcomes can be obtained grades A was $70.74 \%$. Assessment of students in learning lab is an accumulation of the value of knowledge of pre-test and test responses of writing, the value of skills and attitudes of lab activities, preparation of reports, seminars and practice test exams. Based on the results of the study showed that inquiry learning can help the achievement of learning outcomes.
\end{abstract}

Keywords: inquiry, competency, video tutorials, learning outcomes

\section{INTRODUCTION}

Diploma-3 of Chemistry Analyst Department, Islamic University of Indonesia is one of the educational program expertise in chemical analysis has the advantage on Islamic values and laboratory quality management system ISO / IEC 17025. The program of study has been conducted apply educational curriculum has traceable with competency certification system. The study program has undertaken the development of a certification scheme-based learning by applying the Indonesian national qualification framework in the laboratory field in accordance with Regulation of the Minister of Trade No. 79 of 2015 on the Application of the Indonesian National Qualification Framework (KKNI) of Laboratory Examiners. The government regulation policy is closely related to the system of standardization of products and services. 
The Government has prepared the policy in facing industrial harmonization in the global market, especially in facing ASEAN Community with the stipulation of Decree of Minister of Labor Number 345 the Year 2015 about Stipulation of Indonesian Working Competency Standard of Laboratory Testing Service Laboratory Translation from Australian Laboratory Operations Training Package (MSL09). The Professional Certification Institute is developing the existence of the policy, then the entire certification scheme in the field of a laboratory. The development of the KKNI and SKKNI certification scheme is a challenge for a skill education program in the field of chemical analysis to develop a traceable curriculum with certification system in accordance with $\mathrm{KKNI}$ level and possible positions. One of the competency units in KKNI Laboratory Testing Laboratory is preparing, standardizing, and using solution as well as testing and chemical procedures. Achievement of these competencies in the curriculum of Chemistry Analyst Department conducted through Chemistry Analysis II Lab course. The lab of Chemical Analysis II was held in the semester $2^{\text {nd }}$, followed by students who have taken Chemistry Analysis I and Lab of Chemistry Analysis I. The Chemistry Analysis I discussed the basics of the selection methods in chemical analysis, measurement, data processing results of chemical analysis, experimental errors, introductory qualitative analysis of anions and cations, and gravimetric analysis. This course deals with the subject of Chemical Analysis Lab I as a course that plays a role in delivering students to the achievement of competence in testing with chemical procedures by gravimetry.

Lab of Chemical Analysis II course has a weight of 4 (four) credits having relevance to the Chemistry Analysis II course that examines the testing with chemical procedures using a volumetric method. Both of these courses have an important role in the achievement of learning outcome which includes three parameters, which have the ability in the field of work, the scope of work based on knowledge mastered and managerial skills.

Lab of Chemical Analysis II course is conducted in conjunction with the Chemistry of Analysis II course. Students apply volumetric testing practices in the laboratory together with learning the theoretical aspects of various techniques and types of volumetric testing in the Chemistry Analysis II course. Students who follow this course have taken courses in soft-skills of Engineering Laboratories so that students have to understand the performance in the laboratory with good performance. Achievement of competence in testing volumetric should include aspects of knowledge (knowledge), attitude (attitude) and skills (skills) so that students get the learning experience in all dimensions of competence.

The development of learning strategies lab Chemical Analysis II that has been done has some disadvantages. Learning interaction between lecturers, students, and student assistants with less than optimal. Each lecturer has more than 30 students with assistant and student ratio of 1: 8. Lecturer and assistant interaction with the student is very limited to be able to provide guidance in the laboratory so that variable critical on the basic competence of chemical testing such as standard usage of volumetric measure which gives significant influence to the data test result. The practice is not yet standardized and less attractive. The lab module has not been developed on standard methods. The lab module is oriented on aspects of the concept and principle of testing so that during lab learning, the lab module is not yet equipped with the application testing side. Evaluation of learning has not been referring to the standard, not yet using the criteria of performance on the competence standards referred. One of the disadvantages of the lab in vocational education programs is the availability of unstandardized assistants. Not all assistants are from skill education programs so they do not have standardized competencies.

Based on evaluation results, it is indispensable for the development of learning innovation. One alternative application of inquiry learning that has been developed is through the development of video tutorials. Video tutorial development can be an alternative solution in solving learning interaction problems. The development of video tutorials can help students to understand the testing principles and critical variables in basic chemical testing. Lack of lecturer interaction or assistant with students and students' ability in understanding the principles of lab module testing can be a source of error (error) in Lab of Chemistry Analysis II. The development of video tutorials can provide visualization in maintaining lab work in the laboratory in accordance with the lab module. Learning innovation is also followed by improvement of standardized laboratory modules to the application aspect with the application of guarantee system and quality control in ISO / IEC 17025 laboratory standard.

The success of learning with the inquiry model is not measurable from the level of understanding of learners but seen from the level of activity of learners in finding and finding solutions to each problem presented. In contrast, the insufficient level of inquiry model is caused by the lack of learners' role in finding and finding solutions to each problem. 
Based on the above description, in this research will be performed classroom action research to study the influence of video tutorial development in inquiry learning on Chemical Lab Analysis II to the achievement of student competence and improvement of learning outcomes.

\section{LITERATURE REVIEW}

Inquiry learning by Mulyatiningsih [1] is a method that involves learners in the process of data collection and hypothesis testing. Educators guide students to discover new insights, skills practices, and gain knowledge based on their own learning experience. Learners learn actively and creatively to seek knowledge. The inquiry step refers to a reflective thinking model through five stages that begin by identifying problems, formulating hypotheses, collecting data, analyzing and interpreting data to test hypotheses, and drawing conclusions.

Learning steps that will be used are as follows:

1. Explain the purpose of learning

2. Dividing inquiry instructions or practice manuals

3. Assigning learners to implement inquiry

4. Monitor the implementation of inquiry

5. Concluding up the inquiry results together

Inquiry learning can be used in the achievement of chemistry learning competencies [2]. Inquiry learning can improve learning outcomes in the affective, psychomotor and cognitive skills can be measured in four categories of evaluation, student participation, responsibility, curiosity, and discipline.

Aprilia implementing inquiry learning with flash media to determine effectiveness in cognitive, affective and psychomotor spheres for learners [3]. Based on the results of observation and interviews, the existence of flash media in accordance with the needs can make it easy for learners to understand the chemistry learning materials so as to improve learning outcomes.

The use of learning videos in lab activities in the laboratory is considered more effective in improving the ability of observation and technical skills. Through video-based learning can achieve three domains together, namely (1) cognitive level to be able to understand the theory and apply theory to real problems; (2) affective i.e. planning activities independently, cooperating, and communicating information; and (3) psychomotor by learning to install the equipment so that it actually works, using certain tools and instruments [4,5]. The development of inquiry learning with assisting of video tutorial will assist students in understanding the principles and procedures of lab work in the laboratory. Principle understanding is based on the student's theoretical ability to perform an analysis of each stage of the procedure when conducting laboratory practice. Making video tutorials will help students understand every step of the analysis or testing procedure.

\section{METHODS}

This research is a descriptive research. This research was conducted at DIII Chemistry Analyst Department, Faculty of Mathematics and Natural Sciences, Islamic University of Indonesia. The subjects of this study were 62 students of 2nd semester, Academic Year 2015/2016. The research was conducted with six steps as follows:

1. The Revision of Course Outline (CO), Course Schedule (SAP), and Lab Module.

Course outline and SAP are arranged according to the inquiry learning stages using standard format validated by the Head of Chemistry Analyst Department and Dean of Mathematics and Natural Sciences Faculty. Improvement of CO-SAP is done to improve learning strategy from lab method which has been implemented with the standard of Applied Chemistry Laboratory of Chemistry Analyst Department that developed by cooperative learning using inquiry learning method model using video tutorial media [6].

2. Preparing the tutorial video as a learning media for the explanation of the lab module $1-16$.

Video learning that is used as a learning medium to help students in understanding the principles and work procedures in the module so that the process of inquiry learning inquiry more effectively. Video tutorials are developed to make it easier for students to understand the critical aspects of volumetric testing procedures especially in observing the colour change at the endpoint of the titration and reading the etching marks on the volumetric meter.

3. Development of assessment instruments.

An instrument of learning achievement in accordance with performance criteria in the unit of competency referred to $\mathrm{KKNI}$ and SKKNI and student satisfaction value on the implementation of 
learning. Development of self-assessment instrument that refers to SKKNI Field of Laboratory Testers on 3 units of competence:

1) M SL973002A Setting up a working solution

2) MSL974001A Preparesstandardizes and uses the solution

3) MSL974003A Conducts testing and chemical procedures

Validation constructs in instruments are carried out by a competency assessor who has the expertise in developing assessment tools within the competence of the certification system.

4. Assistant briefing

The assistant briefing is conducted to give an explanation to all assistant about learning strategy, learning material, appraisal system and a critical aspect that must be considered to lead the students to the achievement of competence and learning outcomes. An assistant briefing is done by giving an explanation in concept and simulation of inquiry learning on each module of the lab at the same time to make a video tutorial.

5. Lab implementation by the method of inquiry

The lab has been conducted for twenty-eight meetings with sixteen lab modules implemented using inquiry methods. Each class is grouped into eight groups of three to four students and each group at the time of carrying out lab activities is accompanied by one assistant.

Inquiry learning is carried out through five steps:

1. Explain the objectives of Chemistry Lab Analysis II

The lecturer gives an explanation of the learning objectives of Chemical Lab Analysis in accordance with the basic competencies of the courses that have been formulated in the CO-SAP. Through the learning innovation program, the achievement of student competence is focused on three competency units in SKKNI in the field of laboratory testing services, namely

a. MSL973002A Prepares work solution

b. MSL974001A Preparesstandardizes and uses the solution

c. MSL974003A Conducts testing and chemical procedures

2. Divide the inquiry instructions or the Chemical Analysis Lab II module

The teaching lecturer shares instruction inquiry instruction in the form of Chemical Lab Analysis Module II. The lecturer gives an explanation of each practical module on the objectives to be achieved on each lab module, the theoretical review of each principle of volumetric testing, work procedures, and data analysis of the lab results [7].

3. Assigning students to carry out inquiry activities

Lecturers provide inquiry learning tasks in the laboratory. Each group carried out 16 lab modules accompanied by an assistant. Students perform chemical testing activities using the volumetric method according to the inquiry instructions in the lab module. Students are given the opportunity to identify problems and formulate hypotheses [8]. During the inquiry, students collect data on learning outcomes, analyze and interpret data to test hypotheses and draw conclusions. Inquiry learning activities are conducted in four stages, each stage consisting of four module.

Phase I

Module 1. Selection of indicator on acid-base titration

Module 2. Determination of acetic acid in vinegar

Module 3. Determination of fatty acid in soap

Module 4. Determination of $\mathrm{NaOH}$ and $\mathrm{Na}_{2} \mathrm{CO}_{3}$ levels in mixture (Warder way)

Phase II

Module 5. Determination of calcium levels in calcium carbonate

Module 6. Determination of vitamin $\mathrm{C}$ levels with iodometric titration

Module 7. Determination of $\mathrm{Cu}^{2+}$ in $\mathrm{CuSO}_{4} \cdot 5 \mathrm{H}_{2} \mathrm{O}$

Module 8. Formulation of formaldehyde with iodometric titration

Phase III

Module 9. Determination of bromide levels on potassium bromide

Module 10. Determination of chloride content in water sample

Module 11. Determination of chloramphenicol with nitrimetric titration

Module 12. Determination of calcium compleximetrically with EBT indicator

Phase IV

Module 13. Determination of nickel by the titration of complexometry

Module 14. Determination of the degree of hardness of water 
Module 15. Determination of acid-base titration endpoint with potentiometric titration

Module 16. Determination of acidity in water with potentiometric titration

During lab learning activities, the main procedures in chemical testing are recorded so that it will produce a video that will be used to monitor learning and achievement of competence. The inquiry learning video was presented in a seminar on the results of the lab as a source of learning reflection

4. Monitoring the implementation of inquiry learning

Implementation of inquiry learning is monitored by lecturers and assistants at each activity. Inquiry learning activities are accompanied by assistants. One assistant accompanies a group of three to four students. Lecturers monitor all lab activities through inquiry activities of each lab. Practical implementation in detail can be monitored through seminars on the results of the lab of inquiry video video and data recording in the logbook and report of the lab results presented by each group.

5. Concluding he results of inquiry learning

Seminar activity is a process to reflect the result and the learning process so that the student can give the conclusion of the learning result and the learning experience gained during carrying out the inquiry learning task.

6. Seminar on the results of the lab

During the learning process, students record inquiry instruction to be compared with tutorial videos so students can understand the critical aspects of volumetric testing procedures especially in observing the colour change at the end point of the titration and reading the etching marks on the volumetric meter. Student learning video recording can also serve to monitor the achievement of student competencies that can not be observed directly by the lecturer. Records of learning outcomes that have been reviewed through the seminar can enrich the learning media.

7. Evaluation

The evaluation aims to evaluate the achievement of learning and attainment of competence in the learning and assessment of student satisfaction with the lab learning method implemented. Achievement of competence is measured through the test of theory and practice responses after carrying out 2 stages of lab or 8 practical modules.

Evaluation of learning outcomes is measured by pre-test results, performance criterion criteria assessment, report assessment, seminar result of lab and documentation of inquiry learning process. Student satisfaction with inquiry method is measured from questionnaire of lecturer teaching performance evaluation which has been developed by Chemical Analysis Laboratory which becomes component in teaching lecturer performance evaluation.

\section{RESULTS AND DISCUSSIONS}

The development of inquiry learning is accomplished by learning steps through the explanation of learning objectives, dividing the inquiry instructions or practice manuals, assigning learners to carrying out the inquiry, monitoring the implementation of inquiry and summarizing the inquiry results together. Explain the learning objectives and share the inquiry instructions or practice manuals through assistant and assistant training activities with students. Inquiry learning is conducted to assign students to conduct an inquiry in 16 lab work titles and every 4 lab work titles are conducted through the seminar result of the lab so students can reflect on the learning experience. The results of the workshop seminar can give one conclusion together with the learning outcomes that have been done in the laboratory.

\section{Development of Standardized Learning Modules}

Inquiry instruction manual is Chemistry Analysis II Lab Module which will be developed into standardized Chemistry Analysis II Lab Module by applying control and quality assurance of testing at ISO/IEC 17025 laboratory quality management system. Learning module to be used is Chemistry Analysis II Lab Module Edition 2015 which not yet standards that have been validated by a competency assessor who has expertise in chemical analysis. Module validation results can be presented in Table 1.

TABLE 1.The Validation of Chemistry Analysis II Lab Module

\begin{tabular}{clcc}
\hline No & $\begin{array}{c}\text { Component } \\
\text { validation }\end{array}$ & Average rating (0 - 5.00 scale) & Assessment \\
\hline 1 & Eligibility for content & 4.20 & Relevant \\
2 & Language & 4.50 & Relevant \\
3 & Channel & 4.67 & Relevant \\
\hline
\end{tabular}


Based on the validation results show that the Module of Chemistry Analysis II Lab Edition 2015 has good agreement with the average value of 4.46 (scale 0-5) although standardized by the application of controls and quality assurance testing on laboratory quality management system ISO/IEC 17025. The assessment results show that learning modules used have a feasibility content of the material in accordance with the National Competence Indonesia (SKKNI) for the laboratory sector, have eligibility in accordance with the basic competencies, the need for experimental module, and the truth of the material substance.

Validator gives suggestion that the developed of test methods can refer to the standard and nonstandard methods. Each method is accompanied by instructions to the validation or verification method that implement the quality assurance testing on laboratory quality management system ISO/IEC 17025. Data analysis has been presented completely but it is necessary to provide complete analysis and data presentation guidance, as in Experiment 1. Selection of Indicator should include instructions of graph relation of an addition of titrant volume with $\mathrm{pH}$ of the solution which can assist for automatic titration. The module can be completed with learning achievement information that is expected to be in accordance with competency-based curriculum standards.

The results of the validation of the module will be developed into standardized practice modules based on the results of inquiry learning that will be conducted. Through this learning, students will implement reflective thinking models by identifying problems, formulating hypotheses, collecting data, analyzing and interpreting data to test hypotheses and draw conclusions. Students identify problems and formulate hypotheses according to the objectives of each practical module by identifying samples, tools, materials and methods and formulate hypotheses to be tested through lab activities documented in learning video. The resulting data is collected in the logbook as a recording of test results. Students analyze and interpret to test the hypothesis to get the conclusion of the test results.

During the lesson, students are given the opportunity to gain learning experience to identify sample mismatches with test requirements, test result mismatches and presence of data out-of-specificity. The result of reflection on the learning of mercury through the seminar result of the result of the lab can be obtained the conclusion in the development of Chemical Lab Module Analysis II as follows:

1. Each step of the experiment is followed by safety instructions

2. Equipment or instrumentation and materials are given specifications that refer to quality assurance testing

3. Working procedures can be developed using standard methods or non-standard methods equipped with aspects of verification or validation methods

4. Learning Module can be fitted with the procedure check and monitor the quality of the solution.

5. Analysis of the data furnished by the validation or verification calculation and manual methods of data presentation which refers to the quality control testing

6. Testing is done by using the applicable and current test samples

\section{Development Instrument of Assessment}

Instrument of process assessment and learning achievement developed using self-assessment which is used for supporting data of self-assessment toward achievement of student competence toward criteria of performance that exist in unit competence in three competence unit, that is MSL973002A prepare work solution, MSL974001A prepare, standardize and use solution and MSL974003A performed testing and chemical procedures in accordance with this course with SKKNI Field of Laboratory Testing Services from the Australian Laboratory Operations Training Package (MSL09). The validation of instrument constructs is carried out by a competency assessor who has expertise in the development of assessment tools and has technical competence in the field of chemical testing.

TABLE 2.The Validation of Self-assessment Instrument

\begin{tabular}{cccc}
\hline No & $\begin{array}{c}\text { Component } \\
\text { validation }\end{array}$ & Average rating (0 - $\mathbf{5 . 0 0}$ scale) & Assessment \\
\hline 1 & Terms of substance & 4.33 & Relevant \\
2 & Terms of construction & 3.80 & Sufficient \\
3 & Terms of language & 4.33 & Relevant \\
\hline
\end{tabular}


The validation result of self assessment instrumentation can be presented in Table 2. The selfassessment validation results show that the developed assessment instrumentation is in conformity with substance, construction and language requirements. The assessment instruments that have been developed are in accordance with the requirements of the substance of performance criteria in the competency units referred to SKKNI 2015, the competency standards referred to and the conformity of learning achievement indicators with the indicators being tested. The assessment also meets the requirements of construction questions, assessment principles, easy to understand, and has clear and complete information. The developed instrumentation meets the language requirements, effective, efficient and communicative. According to a validator, assessment instruments can be adjusted to routine activities in the laboratory so that students can get a clear picture to conduct self-assessment so that the use of industry-standard language can be adjusted to the language of procedures used in the educational laboratory.

The Influence of Video Tutorial Development in Inquiry Learning into Competence Achievement

The development of tutorial videos in inquiry learning can help the achievement of student competence. Achievement of competence from the knowledge aspect is done by using written test response test data, while from the attitude and skill aspect is measured by practice test response score. Mean of achievement of knowledge competence is $\mathbf{5 7 . 3 4}$ and mean of attainment of competency from attitude and skill aspect is 72.06 .

Competence is an assessment of knowledge, attitudes and skills that can be measured. Chemistry Analysis II Lab Learning is a process of inquiry learning conducted through a series of experiments so that the learning process should be supported by the understanding of the theory concepts that get in the classroom. Practical learning is focused on achieving the competence of work attitude which gives birth to a standardized work culture and skills must be supported with sufficient knowledge.

The supporting data of student competency achievement can be measured through self-assessment in three competency units, i.e. MSL973002A prepare work solution, MSL974001A prepare, standardize and use solution and MSL974003Amelakukan testing and chemical procedures in accordance with this course with SKKNI Field Laboratory Testing Services from the Australian Laboratory Operations Training Package (MSL09). Assessment is done after the students follow the learning process inquiry with the development of learning video. The result of the measurement of achievement of student's average competence in Analytical Chemistry Lab II can be presented in Table 3.

TABLE 3.The Results of student competency achievement

\begin{tabular}{clc}
\hline No & \multicolumn{1}{c}{ Competency Unit } & $\begin{array}{c}\text { Value of } \\
\text { Achievement }\end{array}$ \\
\hline 1 & MSL973002A Preparing work solution & $77.30 \%$ \\
2 & $\begin{array}{l}\text { MSL974001A Prepare, standardize, and use the } \\
\text { solution }\end{array}$ & $79.51 \%$ \\
3 & $\begin{array}{l}\text { MSL974003A Conduct testing and chemical } \\
\text { procedures }\end{array}$ & $78.76 \%$ \\
\hline
\end{tabular}

The average of students' competency achievement at Chemistry Analyst Department on three units of competence is $78.52 \%$. During the learning process lab, students are given learning tasks in preparing work solutions including preparing, standardizing and using the solution. Achievement rates on these units were $77.30 \%$ and $79.51 \%$. Elements of competence that have been achieved both on the unit of competence MSL973002A prepare the working solution is to use laboratory chemicals, glass tools and equipment safely and make the solution work. The learning outcomes indicate the element of competence that needs to be developed is to check the availability of the solution. During the learning process, students always use the newly created solution, so that in the learning activities students can use laboratory stock solution so they can have the opportunity to gain experience in checking the availability of the solution. The results of this assessment are also relevant to the results of the assessment on the achievement of the elements of competence to monitor the quality of the solution in the laboratory in the unit of competence MSL974001A prepare, standardize, and use the solution so that in the improvement of learning can be developed learning modules equipped with procedures to check and monitor the quality of the solution [9].

The result of the assessment shows that the competence unit in preparing, standardizing and using the solution can be achieved with the average achievement of $79.51 \%$ so that the student can be declared 
competent in preparing standard solution, standardize with volumetric tool, record and calculate the standardization data and present the data in value of raw solution concentration.

Students have good achievements in the MSL974003A competency unit performing testing and chemical procedures, including the competence element of interpreting and scheduling test requirements, accepting and preparing samples, checking equipment before use, testing examples to determine the type of compound or its nature, processing and interpreting data, maintain a safe working environment, and maintain laboratory recordings. The competencies that need to be developed in Chemistry Analysis II Lab study are the elements of interpreting and scheduling test requirements and receiving samples. During the learning process of Chemical Lab Analysis II, students get samples from the laboratory and in the module, there is no mention of test requirements and preparation of test samples from the students so that it is necessary to improve the module and learning strategy [10].

\section{Influence of Video Tutorial Development in Learning Inquiry of Learning Outcomes}

The result of the learning development that has been done can give the improvement of the learning result according to the expected target. The end result of learning can be obtained A grade of $70.74 \%$. Assessment of students in learning lab is an accumulation of the value of knowledge of pre-test and test responses of writing, the value of skills and attitudes of practical activities, preparation of reports, seminars and practice test exams. Based on the results of the research shows that the development of video tutorials in inquiry learning can help the achievement of learning outcomes.

Based on the result of research indicate that student have good skill in conducting the examination with volumetry method, but the student still has enough knowledge ability and support chemical basic test competence. The control and quality assurance elements of testing should begin to be applied so as to be relevant to the certification testing scheme in the field of basic chemical testing.

\section{CONCLUSION}

Based on the results of learning that has been done, it can be concluded that the development of inquiry learning can provide the achievement of competence and learning outcomes are influenced by aspects of knowledge, attitude, and skills. The development of learning videos and the implementation of inquiry methods can assist students in achieving competence in working in the laboratory to perform volumetric testing. Inquiry learning methods with the development of enriched modules with learning videos can assist students in achieving learning outcomes.

\section{ACKNOWLEDGMENT}

Authors would like to thank the Board of Academic Development (Badan Pengembangan Akademik) of Islamic University of Indonesia who have given the chance to become the winner of the Regular Teaching Grant Program in the second semester of the 2015/2016 academic year.

\section{REFERENCES}

1. E. Mulyatiningsih, Pembelajaran Aktif, Kreatif, Inovatif, Efektif dan Menyenangkan (PAIKEM),(Direktorat Jenderal Peningkatan Mutu Pendidik dan Tenaga Kependidikan, Jakarta, 2010).

2. B. Amelia, A.T. Widodo, JIPK, 9, 1, 1496-1505(2015).

3. I.T. Aprilia, M. Nuswowati, and E. Susilaningsih, JIPK, 9, 2, 1607-1616(2015).

4. B. Fachera, D. Somantri, and D.L. Hakim, Invotec,8, 2, 115-126(2013).

5. Erniwati, R. Eso, and S. Rahmia, JSPF, 10, 3, 269-273(2014).

6. Daryanto, Media Pembelajaran (Gava Media, Yogyakarta, 2010).

7. Sugiyono, Metode Penelitian Pendidikan Pendekatan Kuantitatif, kualitatif dan R \& D (Penerbit Alfabeta, Bandung 2008).

8. Arikunto, Dasar-dasar Evaluasi Pendidikan (Bumi Aksara, Jakarta, 2008).

9. E. Kazempour, 2013, J.Soc Issues\& Human, 1, 3, 23-27(2013).

10. Roestiyah, Strategi Belajar Mengajar, 7th ed (Rineka Cipta, Jakarta, 2008). 